\title{
Analisis Spasial Deforestasi dan Degradasi Hutan di Suaka Margasatwa Kerumutan Provinsi Riau
}

\author{
Dariono $^{1}$, Yusni Ikhwan Siregar ${ }^{2}$, Nofrizal $^{2}$ \\ ${ }^{1}$ PEH Muda BPKH Wilayah XIX Jl. Majalengka No.101 Kec. Marpoyan Damai Pekanbaru, Riau \\ ${ }^{2}$ Dosen Pascasarjana Ilmu Lingkungan Program Pascasarjana Universitas Riau, Pekanbaru
}

\begin{abstract}
The existence of forests continues to decline in terms of quantity (breadth) and quality through the process of deforestation and forest degradation. Deforestation and forest degradation have an impact on the destruction of ecosystems in the region and reduced forested areas that lead to less optimal functioning of areas as conservation areas. This study aims to determine the rate and rate of deforestation and forest degradation as well as the source of threats in the Kerumutan Wildlife Reserve area. The analytical method used by land cover change with stages: satellite image cutting, classification, groundcheck and analysis of deforestation rate and forest degradation. Classification uses visual interpretation techniques (on screen digitize). Factors affecting deforestation and forest degradation were analyzed by logistic regression. The results show that for 20 years (1996-2016) there has been deforestation of 2,879.73 hectares $(0.15 \%$ per year) and forest degradation of 15,604.92 hectares $(0.83 \%$ per year). Deforestation and forest degradation in SM Kerumutan is influenced by six driving factors such as population density, forest distance from road, forest distance from river, forest distance from settlement, forest distance from agricultural land and forest distance from industrial plantation forest.
\end{abstract}

Key words: deforestation, forest degradation, logistic regression, SM Kerumutan

Salah satu persoalan yang timbul dalam pembangunan kehutanan adalah deforestasi dan degradasi hutan sebagai akibat dari kesalahan dalam pengelolaan dan maraknya aktivitas di luar sektor kehutanan yang membutuhkan lahan hutan. Seiring perkembangan waktu keberadaan hutan terus mengalami penurunan dalam hal kuantitas (luas) maupun kualitasnya melalui proses deforestasi dan degradasi hutan. Deforestasi didefinisikan sebagai kegiatan konversi lahan hutan ke non-hutan yang dilakukan secara langsung oleh aktivitas manusia (Bottcher et al., 2009). Sedangkan degradasi hutan adalah penurunan nilai suatu lahan akibat penurunan kualitas hutan sehingga mempengaruhi fungsi dan potensi hutan tersebut (Winarto, 2006). Deforestasi yang terjadi di Indonesia dipengaruhi oleh berbagai faktor yang sangat kompleks. Margono et al. (2012) menyatakan penyebab utama kerusakan hutan di Indonesia antara lain penebangan liar (illegal logging), pembukaan hutan untuk perkebunan serta kebakaran hutan.
Riau merupakan salah satu provinsi dengan tingkat deforestasi dan degradasi hutan yang cukup tinggi. Periode 1990-2000 deforestasi di Pulau Sumatera sebesar 7,5 juta Ha, rata-rata terbesar kehilangan hutan di Pulau Sumatera terjadi di Provinsi Riau, sebesar $42 \%$. Periode 2009-2011 rata-rata deforestasi tahunan tertinggi di Pulau Sumatera juga terjadi di Provinsi Riau, sebesar 120 ribu ha/tahun (Margono et al., 2012). Deforestasi dan degradasi hutan di Provinsi Riau terjadi pada semua kawasan hutan, termasuk kawasan Suaka Margasatwa (SM) Kerumutan.

SM Kerumutan merupakan kawasan konservasi yang sangat penting sebagai tempat untuk melindungi jenis-jenis flora dan fauna beserta ekosistemnya agar dapat dimanfaatkan untuk kepentingan penelitian, ilmu pengetahuan, pendidikan dan kegiatan lain yang menunjang budidaya. Kawasan ini merupakan kawasan konservasi terluas kedua di Provinsi Riau setelah SM Bukit Rimbang Bukit Baling dan terletak pada kesatuan hidrologis gambut terbesar kedua di Provinsi Riau setelah 
Semenanjung Kampar (BBKSDA, 2016), selain itu kawasan ini merupakan salah satu dari lima benteng terakhir ekosistem rawa gambut di Provinsi Riau (Gunawan, et al., 2013). Deforestasi dan degradasi hutan yang terjadi pada kawasan SM Kerumutan telah berdampak terhadap rusaknya ekosistem di beberapa bagian kawasan ini dan berkurangnya luas kawasan yang berhutan, sehingga menyebabkan kurang optimalnya fungsi kawasan sebagai kawasan konservasi. Pertumbuhan penduduk yang terjadi pada desa-desa yang berada di sekitar kawasan SM Kerumutan yang cukup signifikan diduga sebagai salah satu faktor penyebab terjadinya deforestasi dan degradasi hutan di kawasan ini, selain mudahnya aksesibilitas menuju kawasan SM kerumutan. Mayoritas mayarakat di sekitar kawasan SM Kerumutan bermatapencaharian sebagai petani kebun (karet dan sawit), sehingga melakukan konversi lahan dari hutan menjadi kebun karet dan sawit untuk menopang kebutuhan hidup dan meningkatkan kesejahteraan sangatlah wajar.

Memperhatikan peran penting SM Kerumutan, faktor fisik kawasan dan dinamika sosial ekonomi dan budaya, maka analisis terhadap laju deforestasi dan degradasi hutan serta faktor-faktor yang diduga mempengaruhi (driving factors) di kawasan ini perlu untuk dilakukan. Dengan memahami laju deforestasi dan faktor-faktor penyebabnya maka diharapkan mampu memecahkan permasalahan dari deforestasi dan degradasi hutan SM Kerumutan.

Tujuan dari penelitian ini yaitu:

1. Mengetahui laju deforestasi dan degradasi hutan di SM Kerumutan

2. Menganalisis faktor-faktor yang mempengaruhi deforestasi dan degradasi hutan di SM Kerumutan.

\section{BAHAN DAN METODE}

Penelitian ini dilaksanakan di kawasan hutan SM Kerumutan Kabupaten Pelalawan dan Indragiri Hulu Provinsi Riau serta di Laboratorium SIG BPKH Wilayah XIX Pekanbaru untuk analisis dan pembahasan. Penelitian ini dibagi menjadi empat tahapan yakni tahap persiapan, pengumpulan data dan survey lapangan serta analisis data. Penelitian ini dilakukan bulan Agustus sampai dengan September 2017. Data yang digunakan dalam penelitian berupa citra digital hasil rekaman satelit Landsat yang digunakan yakni citra Landsat TM, Landsat 7 ETM+ dan Landsat 8 OLI, batas wilayah SM Kerumutan, data jaringan jalan, data jaringan sungai, data Ijin Usaha Pemanfaatan Hasil Hutan Kayu-Hutan Tanaman (IUPHHK-HT), data batas administrasi dan data statistik kependudukan Kabupaten Pelalawan dan Indragiri Hulu. Peralatan yang digunakan dalam penelitian ini adalah Global Positioning System (GPS), kamera digital, daftar isian (tally sheet) untuk pengamatan di lapangan. Perangkat pengolahan dan analisis data yaitu seperangkat personal computer dan Software yang digunakan yakni ArcGIS 10.2, IDRISI Selva.

Metode yang digunakan dalam penelitian ini adalah survey ke lapangan untuk mendapatkan data di lokasi penelitian. Obyek penelitian ini adalah kelas penutupan lahan di lapangan. Jenis data yang dikumpulkan adalah data primer dan data sekunder. Data primer berupa data penutupan lahan dilapangan yang diambil berdasarkan purposive sampling dengan pertimbangan kemudahan aksesibilitas dan ketersebaran titik sampel. Pengambilan titik sampel dapat mewakili masing-masing klasifikasi penutupan lahan. Data sekunder yang dikumpulkan dari penelusuran data, baik pada buku, peta, internet, peraturan perundangundangan, penelitian terdahulu maupun dari beberapa instansi terkait baik instansi pemerintah di daerah maupun pusat atau instansi/lembaga independen lainnya.

Deforestasi dan degradasi hutan didapatkan dengan menganalisis perubahan penutupan lahan yang terjadi pada kawasan SM kerumutan. Tahapan analisis ini meliputi pemotongan citra satelit landsat sesuai lokasi penelitian, interpretasi citra/klasifikasi, pengecekan lapangan (groundcheck) dan analisis laju deforestasi dan degradasi hutan. Klasifikasi menggunakan teknik interpretasi visual (on screen digitize). Groundcheck dilakukan untuk mengetahui tingkat akurasi hasil klasifikasi. Nilai akurasi yang disyaratkan tidak kurang dari 85\% (Lillesand et al., 2004). Akurasi dihitung menggunkan rumus :

Kappa Accuracy $=\left[\left(N \sum_{i=1}^{r} X_{i i}-\sum_{i=1}^{r} X_{1+} X_{+1}\right) /\left(N^{2}-\sum_{i=1}^{r} X_{1+} X_{+1}\right)\right]$ 
Overall Accuracy $=\left(\left(\sum_{i=1}^{r} X_{i i}\right) / N\right) x 100 \%$

Ket: $\mathrm{N}=$ jumlah titik penutupan lahan yang divalidasi; $X_{i+}=$ jumlah titik hasil validasi pada jenis penutupan lahan ke-I; $X_{+i}=$ jumlah titik hasil interpretasi pada jenis penutupan lahan ke-i; $X_{i i}=$ jumlah jenis penutupan lahan ke-i hasil interpretasi (baris diagonal)

Laju deforestasi tahunan digunakan rumus:

$$
r=\frac{A_{1}-A_{2}}{t_{2}-t_{1}}
$$

Ket: $r=$ laju deforestasi (ha/tahun); $t_{2}=$ tahun pada waktu akhir; $t_{1}=$ tahun pada waktu awal; $\mathrm{A}_{2}=$ luas hutan pada waktu akhir; $\mathrm{A}_{1}=$ luas hutan pada waktu awal.

Sedangkan untuk persentase laju deforestasi tahunan menggunakan rumus:

$$
V=\frac{\left(A_{1}-A_{2}\right) /\left(t_{2}-t_{1}\right)}{A_{1}} \times 100 \%
$$

Ket: $\mathrm{V}=$ laju deforestasi (\%/tahun); $\mathrm{A}_{1}=$ luas hutan tahun pertama; $\mathrm{A}_{2}=$ luas hutan tahun kedua; $\mathrm{t}_{2}=$ tahun pada waktu akhir; $\mathrm{t}_{1}=$ tahun pada waktu awal.

Untuk mengetahui faktor-faktor yang mempengaruhi deforestasi dan degradasi hutan di SM Kerumutan menggunakan regresi logistik dengan variabel tidak bebas berupa nilai biner $(0=$ tidak terjadi deforestasi dan degradasi hutan dan 1 = terjadi deforestasi dan degradasi hutan) yang merupakan hasil analisis deforestasi dan degradasi hutan periode 1996 sampai 2006. persamaan model regresi logistik adalah (Achmad et al., 2015):

$$
\operatorname{Logit}(Y)=a+b_{1} X_{1}+b_{2} X_{2}+b_{3} X_{3}+\ldots+b_{i} X_{n}
$$

Ket: $\mathrm{Y}=$ variabel dependent $\mathrm{X}=$ variabel independent; $\mathrm{a}=$ Konstanta; $\mathrm{b}_{\mathrm{i}}=$ Koofesien Variabel independent ke $i$, untuk 1, 2, 3, ...p

variabel bebas yang digunakan adalah kepadatan penduduk (jiwa/ $/ \mathrm{km}^{2}$ ), jarak dari jalan $(\mathrm{km})$, jarak dari sungai $(\mathrm{km})$, jarak dari pemukiman $(\mathrm{km})$, jarak dari lahan pertanian (km) dan jarak dari Hutan Tanaman
Industri/HTI (km). Regresi logistik dijalankan menggunakan menu LOGISTICREG pada software IDRISI Selva, dengan metode stepwise yaitu memasukkan variabel bebas satu per satu sampai dengan terakhir dengan menggunakan enam variabel bebas dijalankan secara bersamaan.

\section{HASIL}

\section{Deforestasi dan degradasi hutan}

Hasil interpretasi visual dari citra landsat tahun 1996, 2006 dan 2016 memperoleh klasifikasi tutupan lahan sebanyak tujuh kelas penutupan lahan yaitu hutan rawa primer, hutan rawa sekunder, belukar rawa, perkebunan, tanah terbuka, tubuh air dan rawa. Nilai akurasi hasil klasifikasi tutupan lahan yang dilakukan terhadap data tahun 2016 diperoleh tingkat ketelitian overall accuracy sebesar 91,67\% dan kappa accuracy sebesar 0,90. Nilai akurasi ini telah memenuhi persyaratan minimal yang dikemukakan oleh Jensen (1996) bahwa pada peta penggunaan/penutupan lahan dalam pengelolaan sumber daya alam yang baik dengan akurasi tidak kurang dari $85 \%$.

Hasil klasifikasi penutupan lahan menunjukkan bahwa penutupan lahan di kawasan SM Kerumutan secara keseluruhan (tahun 1996, 2006 dan 2016) didominasi oleh penutupan lahan hutan rawa sekunder (Tabel 1). Hasil klasifikasi tersebut, selanjutnya dilakukan analisis deforestasi, dengan mengelompokkan penutupan lahan menjadi berhutan (hutan rawa primer dan hutan rawa sekunder) dan non hutan (belukar rawa, perkebunan, tanah terbuka, tubuh air dan rawa) untuk mengetahui luas deforestasi dan degradasi hutan selama beberapa periode yaitu periode 1996-2006, 2006-2016 dan periode keseluruhan pengamatan selama 20 tahun (1996-2016).

Tabel 1. Penutupan lahan SM Kerumutan

\begin{tabular}{lrrrrrr}
\hline Penutupan & \multicolumn{2}{c}{ Tahun 1996} & \multicolumn{2}{c}{ Tahun 2006} & \multicolumn{2}{c}{ Tahun 2016 } \\
\cline { 2 - 7 } Lahan & \multicolumn{1}{c}{ Ha } & \multicolumn{1}{c}{$\%$} & \multicolumn{1}{c}{ Ha } & \multicolumn{1}{c}{$\%$} & \multicolumn{1}{c}{ Ha } & \multicolumn{1}{c}{$\%$} \\
\hline Hrp & $43.107,73$ & 45,35 & $29.655,03$ & 31,20 & $25.632,32$ & 26,97 \\
Hrs & $51.027,57$ & 53,69 & $62.731,90$ & 66,00 & $65.620,46$ & 69,03 \\
$\mathrm{Br}$ & 258,63 & 0,27 & $1.795,89$ & 1,89 & $1.755,39$ & 1,85 \\
$\mathrm{Pk}$ & 0,72 & 0,00 & 77,28 & 0,08 & 399,45 & 0,42 \\
$\mathrm{~T}$ & 1,81 & 0,00 & 134,43 & 0,14 & 246,92 & 0,26 \\
$\mathrm{~A}$ & 159,95 & 0,17 & 159,95 & 0,17 & 159,95 & 0,17 \\
Rw & 258,41 & 0,27 & 493,39 & 0,52 & $1.233,38$ & 1,30 \\
\hline Jumlah & $\mathbf{9 5 . 0 4 7 , 8 7}$ & $\mathbf{1 0 0}$ & $\mathbf{9 5 . 0 4 7 , 8 7}$ & $\mathbf{1 0 0}$ & $\mathbf{9 5 . 0 4 7 , 8 7}$ & $\mathbf{1 0 0}$ \\
\hline
\end{tabular}

Sumber : Analisis data, 2017

Ket: Hrp = Hutan rawa primer, Hrs = Hutan rawa sekunder, $\mathrm{Br}=$ Belukar rawa, $P k=$ Perkebunan, $T=$ Tanah terbuka, $A=T u b u h$ air, $R w=$ Rawa 
Hasil dari analisis deforestasi di SM keumutan menunjukkan bahwa pada periode 1996 sampai 2006 telah terjadi deforestasi sebesar 1.746,66 ha dengan laju deforestasi sebesar $174,67 \mathrm{ha} /$ tahun $(0,195 \%$ per tahun). Periode tahun 2006 sampai dengan 2016 terjadi deforestasi sebesar 1.133,07 ha dengan laju deforestasi sebesar 113,41 ha/tahun $(0,12 \%$ per tahun), sehingga selama 20 tahun kawasan hutan SM Kerumutan mengalami deforestasi sebesar 2.879,73 ha dengan laju deforestasi sebesar 143,99 ha/tahun atau $0,15 \%$ per tahun (Gambar 1).

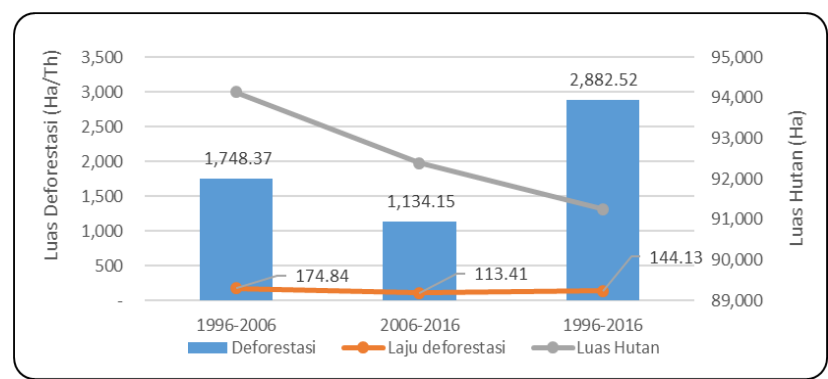

Gambar 1. Luas hutan dan laju deforestasi

Secara spasial sebaran deforestasi tiap periode di wilayah studi tersaji pada Gambar 2.

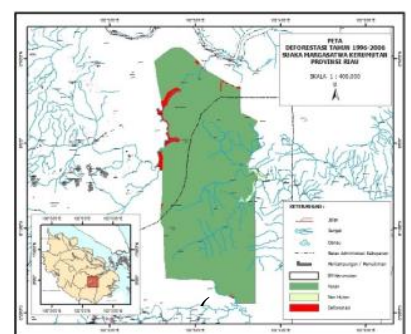

Gambar 2. Sebaran

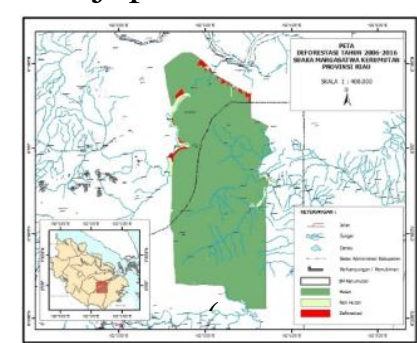

deforestasi di SM
Kerumutan Periode : (a) 1996-2006; (b) 2006-2016

Selain deforestasi, degradasi hutan juga merupakan faktor penyebab perubahan tutupan hutan dan lahan di SM Kerumutan. Hasil analisis menunjukkan bahwa, dari tahun 19962006 terjadi degradasi hutan sebesar 12.263,08 ha dengan laju sebesar 1.226,31 ha/tahun (1,30\% per tahun). Periode 2006-2016 terjadi penurunan degradasi hutan yaitu sebesar 3.991,94 ha dengan laju sebesar 399,19 ha/tahun $(0,43 \%$ per tahun). Selama kurun waktu 20 tahun (1996-2016) SM Kerumutan mengalami degradasi hutan sebesar 15.604,92 ha dengan laju sebesar 780,25 ha/tahun atau $0,83 \%$ per tahun (Gambar 3).

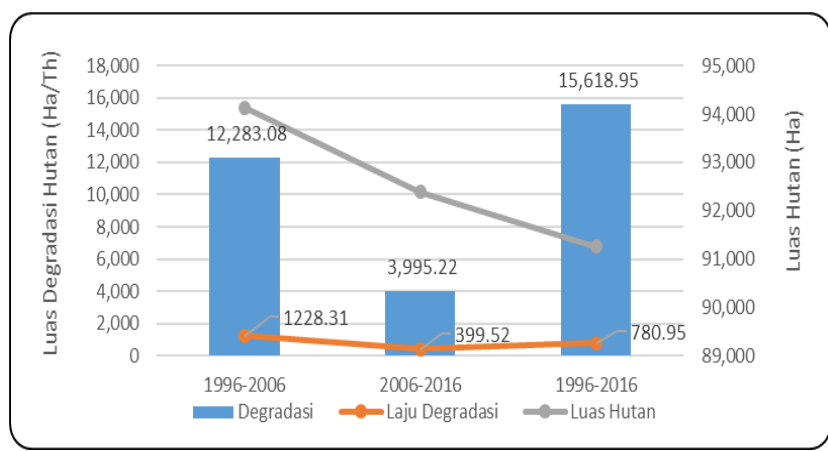

Gambar 3. Luas hutan dan laju degradasi hutan

Sebaran spasial degradasi hutan di SM Kerumutan setiap periode disajikan pada Gambar 4.
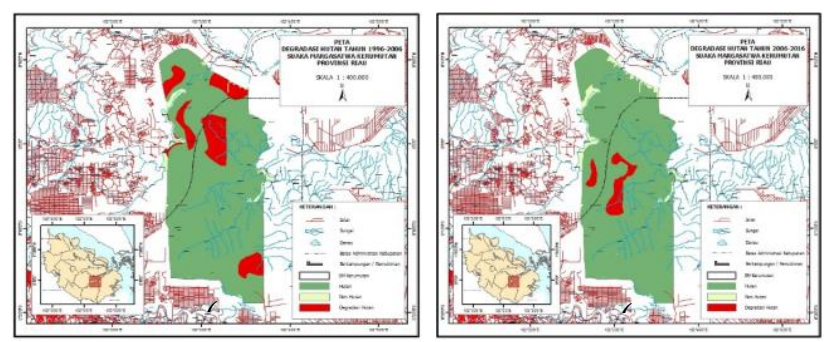

Gambar 4. Sebaran degradasi hutan di SM Kerumutan Periode : (a) 1996-2006; (b) 2006-2016

\section{Faktor-faktor yang mempengaruhi deforestasi dan degradasi hutan}

Persamaan regresi logistik disusun menggunakan enam variabel. Selanjutnya dilakukan analisis derajat keeratan variabel bebas terhadap deforestasi dan degradasi hutan menggunakan analisis Cramer's $V$ (Tabel 2). Pada Tabel 2 terlihat bahwa variabel jarak dari HTI memiliki keeratan yang kuat dengan kejadian deforestasi dan degradasi hutan dengan nilai masing-masing $V$ sebesar 0.362 dan 0,471 , sedangkan variabel bebas yang memiliki keeratan yang kecil adalah kepadatan penduduk dengan nilai 0,118 (deforestasi) dan 0, 174 (degradasi hutan).

Tabel 2. Keeratan hubungan antara variabel bebas dengan kejadian deforestasi dan degradasi hutan

\begin{tabular}{lcc}
\hline \multirow{2}{*}{ Variabel bebas } & \multicolumn{2}{c}{ Cramer's $V$} \\
\cline { 2 - 3 } & Deforestasi & Degradasi hutan \\
\hline Kepadatan penduduk & 0,118 & 0,174 \\
Jarak dari jalan & 0,238 & 0,251 \\
Jarak dari sungai & 0,260 & 0,461 \\
Jarak dari pemukiman & 0,316 & 0,324 \\
Jarak dari HTI & 0,362 & 0,471 \\
Jarak dari lahan pertanian & 0,171 & 0,253 \\
\hline
\end{tabular}


Eastman (2012) menyatakan bahwa analisis Cramer's $V$ menunjukkan hubungan keeratan variabel bebas terhadap variabel terikat, tetapi analisis ini adalah analisis parsial. Oleh karena itu analisis untuk faktor yang mempengaruhi deforestasi dan degradasi hutan secara keseluruhan dilakukan dengan regresi logistik.

Hasil analisis regresi logistik biner dengan metode stepwise menghasilkan enam persamaan yang masing-masing dibedakan oleh jumlah variabel bebas. Koefisien regresi untuk persamaan dengan enam variabel terhadap deforestasi dan degradasi hutan tersaji pada Tabel 3. Nilai koefisien $(\beta)$ menunjukkan hubungan variabel bebas terhadap peluang kejadian deforestasi dan degradasi hutan. Tanda positif dan negatif di depan koefisien regresi menunjukkan arah hubungan variabel bebas. Tanda positif menunjukkan bahwa peningkatan nilai variabel bebas maka meningkatkan peluang deforestasi dan degradasi hutan, sebaliknya tanda negatif menunjukkan bahwa peningkatan nilai variabel bebas menyebabkan penurunan peluang deforestasi dan degradasi hutan.

Tabel 3. Koefisien regresi deforestasi dan degradasi hutan

\begin{tabular}{lrr}
\hline \multirow{2}{*}{ Variabel bebas } & \multicolumn{2}{c}{ Koefisien $(\beta)$} \\
\cline { 2 - 3 } & \multicolumn{1}{c}{ Deforestasi } & \multicolumn{1}{c}{ Degradasi hutan } \\
\hline Konstanta & -2.83987216 & 0.95723181 \\
Kepadatan penduduk & 0,02723707 & 0.28068042 \\
Jarak dari jalan & 0,00062302 & 0.00056890 \\
Jarak dari sungai & $-0,00124706$ & -0.00096553 \\
Jarak dari pemukiman & $-0,00013751$ & -0.00008235 \\
Jarak dari HTI & $-0,00022810$ & 0.00014844 \\
Jarak dari lahan pertanian & 0,00011079 & -0.00005144 \\
\hline
\end{tabular}

Berdasarkan koefisien regresi pada Tabel 3 , persamaan regresi logistik untuk deforestasi adalah: logit $(\mathrm{Y})=-2,8399+0,027237\left(\mathrm{x}_{1}\right)+$ $0,000623\left(\mathrm{x}_{2}\right)-0,001247\left(\mathrm{x}_{3}\right)-0,000138\left(\mathrm{x}_{4}\right)-$ $0,000228\left(\mathrm{x}_{5}\right)+0,000111\left(\mathrm{x}_{6}\right)$, dan persamaan regresi logistik degradasi hutan adalah: logit $\left(\mathrm{Y}_{2}\right)=-0,7503-0,0008778\left(\mathrm{x}_{1}\right)+0,0002308\left(\mathrm{x}_{2}\right)$ $-0,0005508\left(\mathrm{x}_{3}\right)+0,0003314\left(\mathrm{x}_{4}\right)-0,0000042\left(\mathrm{x}_{5}\right)$ $+0,0002625\left(x_{6}\right)$. Hasil analisis regresi logistik menunjukkan bahwa enam variable bebas tersebut berpengaruh nyata terhadap deforestasi dan degradasi hutan.

\section{PEMBAHASAN}

\section{Deforestasi dan degradasi hutan}

Secara keseluruhan laju deforestasi di wilayah penelitian tergolong rendah atau low deforestation (Rijal, 2016). Laju deforestasi hasil penelitian di kawasan ini lebih rendah dari deforestasi yang terjadi pada kawasan SM Balai Raja Provinsi Riau yaitu sebesar 372,41 ha/tahun dari tahun 1990 sampai dengan 2015 (Nainggolan, 2016). Perubahan politik tahun 1998 tidak secara nyata mempengaruhi deforestasi di wilayah penelitian, sebagaimana terjadi di Jawa bahwa terjadi illegal logging sehingga deforestasi meningkat (Nurrochmat dan Hasan 2010). Hasil penelitian ini juga tidak dipengaruhi secara nyata oleh adanya pemberian otonomi daerah pada tahun 1999 seperti hasil penelitian Nawir at al. (2008) yang menyatakan bahwa sejak pemberian wewenang pengelolaan sumber daya alam melalui otonomi daerah tahun 1999, deforestasi meningkat.

Hasil penelitian di SM Kerumutan menunjukkan bahwa degradasi hutan yang terjadi di kawasan ini lebih besar dari deforestasi. Degradasi hutan umumnya disebabkan oleh aktivitas illegal logging bukan konversi hutan menjadi kebun. Hasil pengamatan di lapangan menunjukkan bahwa maraknya aktivitas illegal logging mengakibatkan degradasi hutan di kawasan ini menjadi cukup tinggi. Penelitian ini sesuai dengan hasil penelitian Tacconi, 2007 dalam Kannien et al, 2009 yang menyatakan bahwa di Indonesia, pembalakan ilegal telah muncul sebagai penyebab utama degradasi hutan. Hasil ini juga sejalan dengan penelitian Margono et al. (2012), bahwa illegal logging menjadi penyebab utama degradasi hutan di Sumatera.

\section{Faktor-faktor yang mempengaruhi deforestasi dan degradasi hutan}

Variabel kepadatan penduduk dan jarak dari jalan mempunyai nilai koefisien positif terhadap deforestasi dan degradasi hutan. Persamaan yang diperoleh menyatakan bahwa semakin tinggi kepadatan penduduk maka peluang deforestasi dan degradasi hutan semakin besar. Demikian halnya dengan keberadaan hutan yang semakin jauh jaraknya dari jalan maka peluang terjadinya deforestasi dan degradasi hutan semakin besar. Sementara 
itu, jarak dari lahan pertanian nilai koefisiennya positif terhadap deforestasi, artinya semakin jauh dari lahan pertanian maka peluang deforestasi semakin besar. Sedangkan untuk degradasi hutan variabel ini memiliki nilai koefisien negatif, ini berarti bahwa jarak hutan yang semakin dekat dari lahan pertanian membuat peluang degradasi hutan semakin besar. Variabel HTI memiliki nilai koefisien negatif terhadap deforestasi, artinya semakin dekat hutan dengan HTI, maka peluang deforestasi semakin besar. Sedangkan degradasi hutan, variabel ini koefisiennya positif, hal ini berarti peluang degradasi hutan semakin besar dengan jarak hutan yang semakin jauh dari HTI. Variabel selanjutnya yaitu jarak dari sungai dan jarak dari pemukiman mempunyai koefisien negatif, artinya semakin dekat jarak dari sungai dan pemukiman, maka peluang terjadi deforestasi dan degradasi hutan semakin besar.

\section{SIMPULAN}

Dari hasil penelitian mengenai "Analisis Spasial Deforestasi dan Degradasi Hutan di Suaka Margasatwa Kerumutan Provinsi Riau“ didapatkan kesimpulan sebagai berikut yaitu : 1) Kawasan SM Kerumutan menghadapi tekanan dan ancaman sangat besar, hal ini ditandai dengan terjadinya deforestasi dan degradasi hutan periode 1996-2016, laju deforestasi pada periode tersebut sebesar 143,99 ha/tahun $(0,15 \%$ per tahun) dan laju degradasi hutan sebesar 780,25 ha/tahun (0,83\% per tahun); 2) Faktorfaktor yang berpengaruh terhadap deforestasi dan degradasi hutan di SM Kerumutan yaitu kepadatan penduduk, jarak dari sungai, jalan, pemukiman, HTI dan jarak dari lahan pertanian.

\section{UCAPAN TERIMA KASIH}

Ucapan terima kasih penulis sampaikan kepada Kepala BBKSDA Provinsi Riau dan pihak-pihak lain yang telah membantu dalam masa terlaksananya penelitian ini.

\section{DAFTAR PUSTAKA}

Achmad, A., H. Sirojuzilam, D. Badaruddin, dan N.A. Dwira. 2015. Modeling of Urban Growth in Tsunami-prone City
Using Logistic Regression: Analysis of

Banda Aceh, Indonesia. Applied Geography. 62: 237-246.

BBKSDA. 2016. Blok Pengelolaan Suaka Margasatwa Kerumutan Provinsi Riau. Balai Besar Konservasi Sumber Daya Alam Riau. Pekanbaru

Böttcher, H., K. Eisbrenner, S. Fritz, G. Kindermann, F. Kraxner, I. Mccallum, M. Obersteiner. 2009. An assessment of monitoring requirements and costs of Reduced Emissions from Deforestation and Degradation. Carbon Balance and Management, 4

Eastman, J.R. 2012. IDRISI Selva Tutorial. Clark University.Worcester (US).

Gunawan, H., A. Muhammad, N. Qomar. 2013. Konservasi Indigenous Species Ekosistem Hutan Rawa Gambut Riau. Prosiding Semirata FMIPA Universitas Lampung. Bandar Lampung.

Jensen, J.R. 1996. Introductory digital image processing: A remote sensing perspective. 2nd Edition. Prenctice Hall. New Jersey.

Kannien, M., D. Murdiyaso, F. Seymour, A. Angelsen, S. Wunder dan L. German. 2009. Apakah Hutan Dapat Tumbuh di Atas Uang: Implikasi Penelitian Deforestasi Bagi Kebijakan Yang Mendukung REDD. CIFOR. Bogor.

Lillesand, T.M., Kiefer, R.W. Chipman and W. Jonathan. 2004. Penginderaan Jauh dan Interpretasi Citra. Terjemahan. Gadjah Mada University Press. Yogyakarta

Margono, B.A., S. Turubanova, I. Zhuravleva, P. Potapov, A. Tyukavina, A. Baccini, dan M.C. Hansen. 2012 Mapping and monitoring deforetation and forest degradation in Sumatera (Indonesia) using Landsat time series data sets from 1990 to 2010. Environmental Research Letters 7 (3), 034010.

Nainggolan, T.M., 2016. Analisis Penggunaan Kawasan Hutan Suaka Margasatwa Balai Raja (SMBR) Provinsi Riau.Tesis. Yogyakarta. Program Pascasarjana Fakultas Kehutanan. Universitas Gadjah Mada. Yogyakarta.

Nawir, A.A., Murniati, L. Rumboko. 2008. Rehabilitasi Hutan di Indonesia. Center 
for International Forestry Research. Rijal, S. 2016. Pola Spasial, Temporal dan Bogor.

Nurrochmat, D.R., M.F. Hasan. 2010. Ekonomi Politik Kehutanan: Mengurai Mitos dan Perilaku Deforestasi di Sumatera. Disertasi. Institut Pertanian Bogor. Fakta Pengelolaan Hutan. INDEF. Winarto, B. 2006. Kamus Rimbawan. Yayasan Jakarta. Bumi Indonesia Hijau. Jakarta. 